\section{Oloyede IP Udo PA}

DOI:http://dx.doi.org/10.4314/njp.v43i3.8

Accepted: 19th April 2016

Oloyede IP ( $\boldsymbol{B})$

Udo PA

Department of Paediatrics,

University of Uyo Teaching Hospital,

Uyo Akwa Ibom State, Nigeria.

Email: isooloyede@yahoo.com

\title{
An audit of some health facilities and equipment for neonatal resuscitation in south-south Nigeria
}

\begin{abstract}
Background: Neonatal Mortality rates continue to be high in spite of the general decline in under-5 mortality rates in Nigeria. Available evidence has shown that the availability of a skilled birth attendant and equipment for basic neonatal resuscitation is necessary for the prevention of early neonatal death which accounts for majority of neonatal mortality. This audit was, therefore, carried out to identify the quantity and quality of equipment available for basic neonatal resuscitation in some health facilities in southern Nigeria.

Methods: This was a cross sectional questionnaire based study. Data was obtained from health care workers from 26 health facilities who attended Neonatal resuscitation training workshops from June 2010 to November 2012. Information obtained included type of health facility, obstetric and paediatric services provided and human and material resources available for neonatal resuscitation.

Results: Twenty-three $(88.5 \%)$ were government owned facilities
\end{abstract}

while three $(11.5 \%)$ were private facilities. Of the government owned facilities four were primary health facilities $(17.3 \%), 18$ were secondary $(78.4 \%)$, while only one $(4.3 \%)$ was a tertiary health facility. Most of the health facilities had annual deliveries, annual newborn resuscitation and birth asphyxiated babies in the 1-500 range. All the Paediatricians were in the tertiary health facility. Only three $(11.5 \%)$ facilities had bag and mask and radiant warmer, respectively, while only five $(19.2 \%)$ had radiant warmers.

Conclusion: Equipment for basic neonatal resuscitation is grossly deficient in some health facilities in southern Nigeria. Therefore, urgent efforts should be made by the stakeholders involved in the delivery of child health services to provide basic resuscitation equipment to health facilities. This will contribute to a reduction in the neonatal mortality rate in Nigeria.

Keywords: Neonatal, Resuscitation, Basic, Resuscitation, Equipment.

\section{Introduction}

The child survival indices of 2012 especially the under-5 mortality rate has shown substantial improvement over the 1990 values. ${ }^{1}$ These improvements, however, have not been equitable over geographical regions and across the age ranges. ${ }^{1}$ In Nigeria, the significant improvement seen in the 2012 values over the 1990 values in under five mortality rates (u-5MR) and infant mortality rates (IMR) (124/1000 live births vs 213/1000 live births and 78/ 1000 live births vs 126/1000 live births, respectively) is not appreciable for the neonatal mortality rate (NMR) (39/1000 live births vs $42 / 1000$ live births). ${ }^{1,2}$ This further goes to buttress the fact that most of the improvements in the under-5 mortality rate is due to a fall in the post neonatal mortality rates. Older children have enjoyed the greater gains partly because the most powerful interventions- vaccines, treatment for pneumonia, diarrhoea, malaria and nutritional supplements and bed nets target the leading cause of death for older children. ${ }^{3}$ When it comes to the leading causes of newborn deaths- prematurity, birth asphyxia and infection, simple affordable tools to prevent and treat are often not available at all or not available in the right formulations for newborns. ${ }^{4}$ Newborn deaths may therefore represent the final frontier for child survival. Identifying the facilities, public and private where large numbers of the most vulnerable women are delivering babies especially in the fifteen countries including Nigeria where $80 \%$ of maternal and newborn deaths are concentrated and investing heavily in the quality of care provided in these facilities is of utmost importance and will maximise impact. ${ }^{3}$

Neonatal care provided within the first few minutes of 
life plays a major role in the reduction of neonatal morbidity and mortality. ${ }^{5}$ Internationally there is now considerable consensus on how newborn resuscitation should be provided. ${ }^{6}$ It is believed that in $95 \%$ of cases, when it is required resuscitation should be possible with only a minimum of equipment and without access to intensive care skills or facilities. ${ }^{7,8}$ Immediate newborn assessment and stimulation includes immediate assessment, warming, drying and tactile stimulation at birth. Basic resuscitation is defined as airway clearing (suctioning if required), head positioning and positive pressure ventilation via bag and mask. ${ }^{9}$ Basic resuscitations has been shown to reduce neonatal mortality rate by $20 \%$ generally and preterm mortality in particular has been reduced by $5 \%$. However, in low income countries, particularly in South Asia and sub-Saharan Africa, which account for over two thirds of the world's neonatal deaths, ${ }^{10}$ resuscitation is not available for the majority of newborns who are born either at poorly staffed and equipped first-level health facilities, or at home (60 million births annually), where birth attendants may lack skills or may perform practices that delay effective ventilation. ${ }^{11}$ Given these challenges, achieving high coverage with basic neonatal resuscitation should be prioritized as advanced resuscitation is infrequently required and may have limited additional mortality impact in low resource settings. ${ }^{9}$ To ensure a high proportion of all resuscitation episodes are appropriately managed clearly a large majority of providers must be trained. ${ }^{12}$ However, the availability, accessibility and correct functioning of basic resuscitation equipment is still a missing essential pre-requisite for the successful training and resuscitation itself in many settings. ${ }^{4}$ The provision of resuscitation devices to help babies breathe is one of the cost effective and evidence based but often overlooked commodities for newborn health. ${ }^{13}$

This audit of neonatal resuscitation equipments in health facilities in the state was, therefore, conducted as part of a series of training of health workers in the state in neonatal resuscitation using the American Academy of Paediatrics training manual on neonatal resuscitation. It is hoped that the outcome of this audit will help our health policy makers to prioritize equipment supply for neonatal resuscitation to health facilities in the short term and in the long term assist our trained health workers in resuscitation, therefore improving our neonatal heath indices and reducing neonatal deaths.

\footnotetext{
Methodology

Akwa Ibom State is one of the states in south-south Nigeria. It has borders with Abia, Cross River, Rivers State and Cameroon. It is among the most recently created states in the nation. It has three senatorial districts with 31 local government areas. It has a population of $3,902,051$. $^{14}$ Most of the urban dwellers are civil servants, while the indigenous occupation of the people is farming and fishing. It has an infant mortality rate of 66 per 1000 live births and an under-five mortality rate of
}

102 per 1000 live births. ${ }^{15}$ These values are a lot higher than the WHO recommended values. Most $(>60 \%)$ of the births occur outside the health facility. There are 405 health facilities in Akwa Ibom State; 361 are primary, 49 are secondary, with one tertiary health facility. ${ }^{16}$

We conducted neonatal resuscitation training (NRT) using the American Academy of Paediatrics (AAP) training manual in conjunction with the State Ministry of Health, Akwa Ibom State with participants drawn from 26 health facilities from the three senatorial districts of the state. The participants were doctors and nurses from the primary through the tertiary health care facilities. The training occurred from June 2010 to November 2012.

The facilitators had been trained and certified in the NRT train-the trainers program of the AAP conducted by the Paediatric Association of Nigeria (PAN) in collaboration with the Latter day Saint's Charities. The studies were approved by the ethical committee of the University of Uyo Teaching Hospital

A train-the-trainer educational programme utilized various teaching methods for participants learning including clinical practice sessions and demonstrations with mannequins and case scenarios to train health professionals. Two-day training programmes were held for not more than 60 participants at a time. These trainings were held biannually.

The neonatal resuscitation course content included an in depth hands on training in basic knowledge and skills including initial resuscitation steps, bag and mask ventilation, chest compression, endotracheal intubation, medications, ethics and end of life care. Mannequins were used for the hands-on demonstrations and each participant was encouraged to practice the skills taught and observed. The training lasted for two days. Participants filled a pre-training questionnaire indicating the annual number of deliveries and number of asphyxiated babies in their facility, their resuscitation practices and the human and material resources available in their centre for neonatal resuscitation. The list of equipments was derived from the neonatal resuscitation textbook of the American Academy of Paediatrics and adapted to our local context. ${ }^{17}$ This was to enable us assess the preparedness of the facilities for resuscitation and to assess if the participants had the equipments to work with after the training.

\section{Data analysis}

The statistical package STATA (Stata Corp TX USA) was used to analyze the data. Results were summarized as means and standard deviations and presented in tables. A p-value of $<0.05$ was taken as statistically significant.

\section{Results}

Twenty-six health facilities were assessed for material 
and human resources for neonatal resuscitation. Seven $(26.9 \%)$ of the health facilities were in the Eket senatorial district, $11(42.3 \%)$ in Ikot Ekpene senatorial district and Eight $(30.8 \%)$ of the facilities were located in Uyo Senatorial district. Twenty-three $(88.5 \%)$ were government owned facilities while three $(11.5 \%)$ were private facilities. Of the government owned facilities four were primary health facilities $(17.3 \%), 18$ were secondary $(78.4 \%)$, while only one $(4.3 \%)$ was a tertiary health facility. Table 1 shows that most of the health facilities provide some level of obstetric care, while table 2 shows that neonatal intensive care is not provided by most of the health facilities.

Table 1: Spectrum of obstetric services provided by some
Health facilities in Southern Nigeria
\begin{tabular}{llllll} 
Services & Obstetric & ANC $^{*}$ & CS & FP $^{\dagger}$ & VD $^{\ddagger}$ \\
\hline Yes & 25 & 26 & 22 & 23 & 22 \\
No & 1 & 0 & 4 & 3 & 4 \\
\hline
\end{tabular}

*Antenatal Care; Caesarean Section; †Family Planning; $\ddagger$ Vaginal delivery

\begin{tabular}{|c|c|c|c|c|c|}
\hline Services & POP* & PIP & $\begin{array}{l}\text { Routine } \\
\mathrm{NB}^{\dagger} \text { care }\end{array}$ & $\mathrm{NIC}^{\ddagger}$ & Immunization \\
\hline Yes & 24 & 22 & 21 & 7 & 23 \\
\hline No & 2 & 4 & 5 & 19 & 3 \\
\hline
\end{tabular}

*Paediatric Outpatient; Paediatric Inpatient; ${ }^{\dagger}$ New-born;

${ }^{\ddagger}$ Neonatal Intensive Care

Table 3 shows that most of the health facilities had annual deliveries, annual newborn resuscitation and birth asphyxiated babies in the 1-500 range. The tertiary health facility was the only facility with greater than 2000 deliveries per annum (precisely 5000-6000 births). The distribution of health professionals especially paediatricians was quite low in the health facilities as shown in table 4.

\begin{tabular}{|c|c|c|c|c|c|c|}
\hline Parameter & None & $\begin{array}{l}1- \\
500 \\
\end{array}$ & $\begin{array}{l}\text { Fre- } \\
\text { quency } \\
501- \\
1000 \\
\end{array}$ & $\begin{array}{l}1001- \\
1500 \\
\end{array}$ & $\begin{array}{l}1501- \\
2000 \\
\end{array}$ & $>2000$ \\
\hline Annual deliveries & 4 & 17 & 1 & 1 & 1 & 1 \\
\hline $\begin{array}{l}\text { Newborn resuscita- } \\
\text { tion }\end{array}$ & 4 & 20 & 1 & 0 & 0 & 0 \\
\hline Asphyxiated babies & 4 & 20 & 1 & 0 & 0 & 0 \\
\hline
\end{tabular}

Table 4: Distribution of healthcare professionals in some facilities in southern Nigeria

\begin{tabular}{llllllll}
$\begin{array}{l}\text { Health pro- } \\
\text { fessionals }\end{array}$ & None & $1-10$ & $11-20$ & $21-30$ & $\begin{array}{l}31- \\
40\end{array}$ & $41-50$ & $>50$ \\
\hline $\begin{array}{l}\text { Skilled birth } \\
\text { attendants }\end{array}$ & 6 & 14 & 0 & 2 & 1 & 0 & 2 \\
Midwives & 3 & 15 & 3 & 3 & 0 & 2 & - \\
Med officers & 1 & 24 & 1 & 0 & 0 & 0 & 0 \\
Obstetrician & 17 & 8 & 1 & 0 & 0 & 0 & 0 \\
Paediatrician & 21 & 5 & 0 & 0 & 0 & 0 & 0 \\
Anaesthetist & 6 & 20 & 0 & 0 & 0 & 0 & 0 \\
\hline
\end{tabular}

The distribution of equipments for basic neonatal resuscitation especially bag and mask (11.5\%), radiant warmer $(11.5 \%)$ and pre-warmed towels $(19.2 \%)$ were very poor in the health facilities as shown in table 5 . On the other hand, most facilities seemed to have the drugs required for advanced resuscitation as shown in table 6 .

\begin{tabular}{llllllll}
\hline \multicolumn{2}{l}{ Table 5: Distribution of basic newborn resuscitation equipments in some health facilities in southern Nigeria } \\
Equipment & $\begin{array}{l}\text { Neonatal } \\
\text { bag/mask }\end{array}$ & $\begin{array}{l}\text { Suction } \\
\text { machine }\end{array}$ & Stethoscope & $\begin{array}{l}\text { Suction } \\
\text { catheter }\end{array}$ & Timers & Radiant & Pre-warmed \\
& & & warmer & towels \\
\hline Yes (\%) & $3(11.5)$ & $19(73.1)$ & $24(92.3)$ & $14(53.8)$ & $6(23.1)$ & $3(11.5)$ & $5(19.2)$ \\
No $(\%)$ & $23(88.5)$ & $7(26.9)$ & $2(7.7)$ & $12(46.2)$ & $20(76.9)$ & $23(88.5)$ & $21(80.8)$ \\
\hline
\end{tabular}

Table 6: Distribution of advanced newborn resuscitation equipment in some health facilities in southern Nigeria

\begin{tabular}{lll} 
Equipments & Yes $(\%)$ & No $(\%)$ \\
\hline Oxygen cylinders & $14(53.8)$ & $12(46.2)$ \\
Oxygen concentrators & $6(23.1)$ & $20(76.9)$ \\
Neonatal laryngoscope & $2(7.7)$ & $24(92.3)$ \\
Endotracheal tubes & $2(7.7)$ & $24(92.3)$ \\
Nasogastric tube & $20(76.9)$ & $6(23.1)$ \\
Meconium aspirator & $2(7.7)$ & $24(92.3)$ \\
Umbilical catheter & $2(7.7)$ & $24(92.3)$ \\
Resuscitaire & $2(7.7)$ & $24(92.3)$ \\
$0.9 \%$ saline & $26(100)$ & $0(0)$ \\
10\% D/W & $22(84.6)$ & $4(15.4)$ \\
Adrenaline & $25(96.2)$ & $1(3.8)$ \\
8.4\% Sodium bicarbonate & $13(50)$ & $13(50)$ \\
Whole blood & $17(65.4)$ & $9(34.6)$ \\
\hline
\end{tabular}

\section{Discussion}

The distribution of health facilities in the state is reflective of that of the nation with $88.5 \%$ being government owned with a highlight on the disparities among different local governments in the state. ${ }^{18}$ Our results show a general dearth of basic resuscitation equipment in our health facilities especially in the primary and secondary healthcare facilities. These results provide a possible explanation for our inability to effectively bring down the neonatal mortality rate in our country. This corroborates the already known fact that majority of new-borns are born either at poorly staffed and equipped first-level health facilities, or at home. With the relatively low government funding of health of less than $5 \%$ of the Gross Development Product, and an increasing reliance on household out-of- pocket expenditure for health, it is not surprising that provision of basic resuscitation equipment and skilled health personnel in the health facilities are very poor. ${ }^{18}$ However, the availability of drugs (84$100 \%$ ) which are needed for advanced newborn resuscitation point to organisational and management deficiencies related to weak, fragmented and inconsistent linkages between the different stakeholders in the delivery of child health services. Moreover, the high burden of annual deliveries in the tertiary centre compared to that seen in the primary and secondary centres likely results 
from a combination of poverty, societal and cultural factors which constitute barriers to accessing healthcare in rural communities. In addition, this maybe an indicator of non-functional primary and secondary healthcare facilities or a lack of confidence in the operation of the primary and secondary health services by the populace. Our results also point to the inequalities in accessing healthcare at the different levels especially in the distribution of health personnel where majority are found in the tertiary institution. This brings up the need for staff recruitment to fill up the established posts in the periphery and the provision of essential equipment for basic new-born resuscitation.

The major limitation of this study was the fact that the self-reported questionnaires used may give some room for recall bias but considering the poor record keeping prevalent in our setting it was difficult to get data from an alternative source.

\section{Conclusion}

In conclusion, basic neonatal resuscitation equipment is largely unavailable in health facilities in South-south Nigeria which may partly explain the prevailing high infant mortality rate in this region.

We, therefore, recommend collaboration among the different stakeholders that deliver child health services on the provision of basic neonatal resuscitation equipment. This is particularly important in the absence of high-technology innovations that are available in the high income countries for the tertiary prevention and treatment of neonatal encephalopathy. ${ }^{19}$ In addition, there is need for interventional studies in our setting to define strategies to overcome this challenges in order to drive policy changes. Furthermore, there is an urgent need to strengthen the Primary and Secondary health care system to provide comprehensive and competitive basic neonatal resuscitation services by encouraging community ownership through informed decision making and accountability of resources allocated to neonatal resuscitation services.

\section{Conflict of interest: None \\ Funding: None}

\section{Acknowledgements}

The authors wish to thank Akwa Ibom State Ministry of Health for funding two of the training sessions and Nestle Nutrition Institute Africa for funding one of the training sessions. We also acknowledge the help of $\mathrm{Dr}$ Udeme Ekrikpo in Data Analysis.

\section{References}

1. The United Nations Children Fund. The state of the world children 2014 in numbers. Every child counts: Revealing Disparities advancing children's right. UNICEF New York 2014. Pg 33.

2. National Population Commission (NPC) [Nigeria] and ICF Macro. 2009. Nigeria Demographic and Health Survey 2008. Abuja, Nigeria: National Population Commission and ICF Macro

3. Greenslade L. Newborn deaths the final frontier in the battle for child survival. http//www.mdghealth envoy.org. downloaded on $3^{\text {rd }}$ March 2014

4. Lawn JE, Cousens S, Zupan J: 4 million neonatal deaths: when? Where? Why? Lancet 2005, 365 (9462):891-900.

5. Duran R, Aladiq N, Vatansever U, Sat N, Alunas B. The impact of neonatal resuscitation programme courses on mortality and morbidity of newborn infants with perinatal asphyxia. Brain Dev 2008; 30(1): 43-46

6. International Laison Committee on Resuscitation. 2005 International Consensus on Cardiopulmonary Resuscitation and Emergency Cardiovascular Care Science with Treatment Recommendations. Part 7: Neonatal resuscitation. Resuscitation 2005;67.doi 10.1016/j.resuscitation 2005.09007
7. WHO. Basic newborn resuscitation: a practical guide. $1997 \mathrm{Ge}$ neva World Health Organisation.

8. Opiyo N, English M. Newborn resuscitation: defining best practices for low-income settings. Trans R Soc Trop Hyg 2006; 100:899-908.

9. Lee AC, Cousens S, Wall SN, et al. Neonatal resuscitation and immediate newborn assessment and stimulation for the prevention of neonatal death, a systematic review, metanalysis and Delphi estimation of mortality effect. $B M C$ Public Health 2011;11(3): S12

10. Wall SN, Lee AC, Niermeyer S, English M, Keenan WJ, Carlo W, Bhutta ZA, Bang A, Narayanan I, Ariawan I, et al: Neonatal resuscitation in low resource settings: what, who, and how to overcome challenges to scale up? Int J Gynaecol Obstet 2009; 107(Suppl 1):S47-62-S63-44.

11. English M, Esamai F, Wasunna A, et al. Delivery of Paediatric Care at the first referral level in Kenya. Lancet 2004; 364:1622-29.

12. Oloyede IP, Udo PA, Nyong EE. Effectiveness of didactic training on the cognitive knowledge of health professionals on neonatal resuscitation in southern Nigeria. Niger J Paed 2015; 42 (2): 88-92.
13. PMNCH knowledge Summary \#29. Delivering our future: survival and health for every newborn. The partnership for maternal Newborn and Child Health.2014. http://www.who.int/pmnch/ knowledge/publications/ summaries/ks29/e/

14. Report of the 2006 census final results. Federal Republic of Nigeria Official Gazette 2009;96:B22.

15. Millennium Development Goal Report Akwa Ibom State 2012

16. Akwa Ibom State Ministry of health/ Nigeria Medical Association 2014 Report

17. American Academy of Paediatrics. Textbook of neonatal resuscitation. Ed. Kattwinkel J. Sixth edition 2011. American Academy of Paediatrics and American Heart Association. Pg 29-31

18. WHO country cooperation strategy 2014-2019 Nigeria. WHO regional office for Africa. 2014

19. Lawn J.E, Lee A.C, Kinney M, et al. Two million intrapartumrelated stillbirths and neonatal deaths: Where, why, and what can be done? Int J Gynecol and Obst 2009;107: S5-S19s 